\title{
The classic elephant trunk technique for staged thoracic and thoracoabdominal aortic repair: Long-term results
}

\author{
Sebastiano Castrovinci, MD, ${ }^{\mathrm{a}, \mathrm{b}}$ Giacomo Murana, MD, ${ }^{\mathrm{a}, \mathrm{b}}$ Gijs E. de Maat, MD, ${ }^{\mathrm{a}}$ Tim Smith, MD, PhD, ${ }^{\mathrm{a}}$ \\ Marc A. A. M. Schepens, MD, PhD, ${ }^{c}$ Robin H. Heijmen, MD, PhD, ${ }^{a}$ and Wim J. Morshuis, MD, PhD ${ }^{a}$
}

\section{ABSTRACT}

Objective: The classic elephant trunk (ET) technique has become the standard approach for patients with diffuse aortic disease requiring a staged thoracic and thoracoabdominal aortic repair. The aim of this study was to assess long-term outcomes and predictors for survival after surgical repair of extensive thoracic aortic disease with the ET technique.

Methods: Between 1984 and 2013, 248 consecutive patients were treated in our institution and analyzed retrospectively. Follow-up consisted of outpatient clinic visits including postoperative computed tomography imaging at 3 months and annually thereafter. Second-stage intervention was indicated if the diameter of the descending or thoracoabdominal aorta was greater than or equal to $60 \mathrm{~mm}$, in case of a rapidly growing aneurysm and/or symptoms.

Results: Mean age was $65 \pm 10$ years; $44 \%$ were male. After first-stage ET, inhospital mortality was $8 \%$ and permanent neurologic deficits were observed in $2 \%$ of patients. Median follow-up after the first stage was 48 months (range, 1210 months). One hundred twelve patients (45\%) underwent second-stage ET. Overall survival after first-stage ET was $75 \%$ and $67 \%$ at 5 and 10 years, respectively. Survival in patients with second-stage ET was $87 \%$, compared with $65 \%$ in the group who did not undergo second-stage ET at the 5-year follow-up $(P<.001)$ and $67 \%$ compared with $36 \%$ at the 10 -year follow-up $(P<.001)$. Predictor for mortality was the absence of second-stage ET $(P=.044)$.

Conclusions: A 2-stage approach for diffuse aortic disease is a safe method. The acceptable mortality at the first stage justifies the use of the classic ET technique and allows subsequent repair of the distal aorta. Long-term survival is increased when both stages are completed. (J Thorac Cardiovasc Surg 2015;149:416-22)

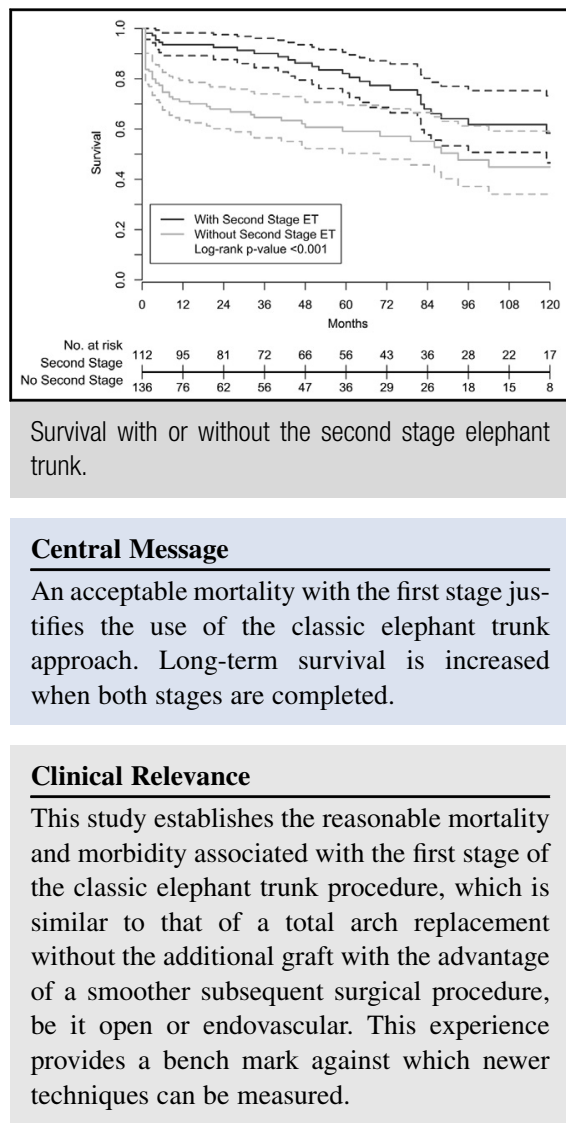

See Editorial Commentary pages 423-4.
The management of extensive aortic disease remains a surgical challenge because of the extent of aortic involvement and the morbidity and mortality associated with repair.

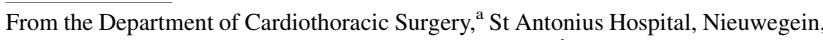
The Netherlands; Department of Cardiac Surgery, ${ }^{b}$ University of Bologna, Sant'Orsola-Malpighi Hospital, Bologna, Italy; and Department of Cardiovascular Surgery, ${ }^{c}$ AZ St Jan Hospital, Brugge, Belgium.

Disclosures: Authors have nothing to disclose with regard to commercial support.

Received for publication July 9, 2014; revisions received Sept 4, 2014; accepted for publication Sept 23, 2014; available ahead of print Oct 22, 2014.

Address for reprints: Sebastiano Castrovinci, MD, Cardiac Surgery Division, Sant'Orsola-Malpighi Hospital, Alma Mater Studiorum, University of Bologna, Via Massarenti n 9, 40138 Bologna, Italy (E-mail: sebastiano.castrovinci@ gmail.com).

$0022-5223 / \$ 36.00$

Copyright (c) 2015 by The American Association for Thoracic Surgery

http://dx.doi.org/10.1016/j.jtcvs.2014.09.078
}

Ascending aorta, arch and descending thoracic aorta replacement, carried out in a single stage, requires multiple incisions, longer extracorporeal circulation times, prolonged procedures, and is associated with more blood loss. ${ }^{1-3}$ When the operation was carried out in 2 steps, there was a high risk of bleeding from distal anastomosis during the second step. ${ }^{4}$ To reduce these complications, Borst and colleagues ${ }^{5}$ introduced the elephant trunk (ET) technique in 1983, which leaves a freefloating segment of graft in the descending aorta to aid the second-stage graft-to-graft anastomosis. Since its introduction, the classic ET technique has become the standard approach for patients with diffuse aortic disease requiring a 2 -stage repair. The first stage is the ascending and/or arch replacement and the second stage consists of 


\section{Abbreviations and Acronyms \\ ASCP = antegrade selective cerebral perfusion \\ $\mathrm{CT}=$ computed tomography \\ ET = elephant trunk \\ FET $=$ frozen elephant trunk \\ ICU = intensive care unit \\ SCI = spinal cord injury \\ TEVAR $=$ thoracic endovascular aortic repair}

descending thoracic or thoracoabdominal repair. ${ }^{6}$ The aim of this study was to assess long-term outcomes after surgical repair of extensive thoracic aortic disease using the 2stage approach with the classic ET technique as the first stage.

\section{MATERIALS AND METHODS Patient Population}

Between September 1984 and September 2013, 248 consecutive patients underwent an ET procedure at St. Antonius Hospital, Nieuwegein, The Netherlands. Patients underwent surgery for extensive thoracic aortic diseases; 156 degenerative aneurysms $(63 \%), 86$ chronic postdissection aneurysms (35\%), and 5 acute type A aortic dissections ( $2 \%)$. No patient was intentionally excluded. We retrospectively divided the patients into 2 groups, based ob completion of the second stage. The ethical committee of our institution approved this observational retrospective study.

\section{Surgical Techniques}

Proximal repair, first-stage ET. Cannulation site and myocardial protection. The arterial cannula was inserted into the distal ascending aorta (39\%), the femoral artery (30\%), the aortic arch $(28 \%)$ or, rarely, the right axillary artery $(3 \%)$. Venous cannulation of the right atrium or the common femoral vein was performed using a 2-stage cannula. Myocardial protection was achieved with cold antegrade crystalloid cardioplegia, maintaining the interventricular septal temperature at less than $10^{\circ} \mathrm{C}$ with continuous topical cooling of the heart.

Cerebral protection. Deep hypothermic circulatory arrest (isoelectric electroencephalogram and/or rectal or nasopharyngeal temperature of $18^{\circ} \mathrm{C}$ or lower), uni- or bilateral antegrade selective cerebral perfusion (ASCP) with moderate hypothermia (nasopharyngeal temperatures of $22-25^{\circ} \mathrm{C}$ ) or a combination of both (ASCP under simultaneous conditions of deep hypothermic circulatory arrest) were used for cerebral protection. These techniques have been described previously. ${ }^{7}$ No retrograde cerebral perfusion was used in this series.

Distal anastomosis management. At the beginning of our experience, we used the modified Borst technique as described by Crawford and colleagues. ${ }^{8}$ A long stay suture marked the proximal end of the Dacron prosthesis, which was invaginated into the trunk; the suture facilitated the unfolding process, and the amount of invagination determined the length of the trunk. The resulting double-layered graft was inserted into the descending aorta, just distally from the origin of the left subclavian artery (according to Svensson and colleagues' type I classification). ${ }^{9}$ The distal anastomosis was completed by suturing the end of the double-layered graft to the proximal descending aorta and subsequently unfolding the prosthesis by pulling the stay suture. Next, an elliptical opening was made to reimplant the cerebral vessels using an island technique. Particular tips and modifications of the technique have previously been described for acute and chronic aortic dissection. ${ }^{10}$ From 1996, prefabricated aortic arch prostheses with 4 branches for the cerebral vessels (InterGard Aortic Arch; InterVascular,
MAQUET Cardiovascular, La Ciotat, France) or a single side branch for antegrade arterial perfusion (InterGard HemaBridge; InterVascular, MAQUET Cardiovascular, La Ciotat, France) were used more frequently. From that time, the distal part of the prosthesis was inserted into the descending aorta and sutured taking side bites on the prosthesis. Starting in 2009, Gelweave Anteflow 1-branched or 4-branched arch prostheses (Vascutek, Inchinnan, United Kingdom) were used. From 2010 onward, a prefabricated aortic arch graft with a sewing collar (Vascutek Siena, Inchinnan, United Kingdom) was used, both the anteflow 1-branched or 4-branched version. The collar minimizes the tension on the distal anastomosis and potentially reduces the risk of pseudoaneurysm formation before the second-stage intervention. ${ }^{11}$ Radiopaque tantalum markers are located along the length of the graft to facilitate the second-stage repair using endovascular techniques.

Distal repair, second-stage ET. The repair was performed via a left thoracotomy, thoracoabdominal, or endovascular approach. Cerebrospinal fluid drainage, somatosensory evoked potentials, and motor-evoked potentials were used routinely. Distal aortic perfusion was established with a left heart bypass, cannulating the pulmonary vein or left atrial appendage and the common femoral artery. The middle part of the descending thoracic aorta was clamped and the proximal part of the descending aneurysm (where the ET was expected to be) was opened longitudinally; the ET was grasped and clamped and the new graft was sutured to the ET. Sequential clamping of the descending or thoracoabdominal aorta was performed in order to reattach the intercostal arteries, the visceral arteries, and finally distal aortic anastomosis.

\section{Follow-up}

All patients visited the outpatient clinic according to the standard care protocol for patients treated for extensive aortic disease. ${ }^{6}$ After the first stage, patients were evaluated using computed tomography (CT) scan at 3 months and annually thereafter. Second-stage intervention was scheduled if the diameter of the descending or thoracoabdominal aorta was $60 \mathrm{~mm}$ or more for degenerative aneurysms ( $\geq 50 \mathrm{~mm}$ for connective tissue disease), for rapidly growing aneurysms, or when symptoms were present. Because of the observational nature of the study, patients were not subjected to any specific additional investigations.

\section{End Points}

The primary end point was survival after first- and second-stage surgery. The secondary end point was the occurrence of procedural and postprocedural adverse events. An adverse event was defined as an event resulting in death or permanent injury, in temporary injury requiring intervention or specific treatment (eg, permanent or temporary neurologic deficit, transient ischemic attack, major bleeding requiring surgery or cardiac tamponade, myocardial infarction, mediastinitis, respiratory failure, temporary or permanent dialysis, pacemaker implantation, spinal cord injury, left recurrent nerve injury, and other undefined events).

\section{Statistical Analysis}

Baseline descriptive statistics are presented as the mean \pm standard deviation or median (range) for continuous variables, as appropriate, and as counts with percentages for categorical variables. Differences between subgroups were evaluated by the Student $t$ test or the Mann-Whitney $U$ test for continuous data, depending on the normality of the data; the $\chi^{2}$ or Fisher exact test was used for comparison of categorical variables. Kaplan-Meier analysis was used to assess survival; patients were censored at the time of death, time of loss to follow-up, or on February 1, 2014, whichever occurred first. The time to event was calculated as the time from the first- and second-stage surgery until censoring. Univariate predictors with a $P$ value less than .1 were tested in multivariate logistic regression analyses. The regression analyses were used to investigate the independent associations of the baseline characteristics with the primary end point. In the final multivariate model, only variables with a $P$ value 
TABLE 1. Baseline characteristics of patients undergoing ET, with and without the second-stage ET technique

\begin{tabular}{|c|c|c|c|c|}
\hline & $\begin{array}{c}\text { Total ET group } \\
\text { first stage }(n=248)\end{array}$ & $\begin{array}{c}\text { Group without } \\
\text { second-stage ET }(n=136)\end{array}$ & $\begin{array}{c}\text { Group with } \\
\text { second-stage ET }(n=112)\end{array}$ & $P$ value \\
\hline Age, $y \pm S D$ & $65 \pm 10$ & $51 \pm 10$ & $53 \pm 9$ & .947 \\
\hline Male, n (\%) & $109(44)$ & $58(43)$ & $51(46)$ & .700 \\
\hline EuroSCORE I, \pm SD & $8.6 \pm 1.6$ & $9.0 \pm 1.7$ & $8.2 \pm 1.5$ & .140 \\
\hline Bicuspid valve, n (\%) & $2(1)$ & $2(1)$ & $0(0)$ & .503 \\
\hline Marfan, n (\%) & $20(8)$ & $9(7)$ & $11(10)$ & .483 \\
\hline COPD, n $(\%)$ & $28(11)$ & $13(10)$ & $15(13)$ & .421 \\
\hline Renal failure, n (\%) & $3(1)$ & $1(1)$ & $2(2)$ & .592 \\
\hline $\mathrm{CAD}, \mathrm{n}(\%)$ & $48(19)$ & $26(19)$ & $22(20)$ & .917 \\
\hline Diabetes, n (\%) & $10(4)$ & $3(2)$ & $7(6)$ & .193 \\
\hline Smoking, n (\%) & $16(7)$ & $5(4)$ & $11(10)$ & .068 \\
\hline Hypercholesterolemia, n (\%) & $16(7)$ & $8(6)$ & $8(7)$ & .797 \\
\hline Hypertension, n (\%) & $164(66)$ & $85(63)$ & $79(71)$ & .225 \\
\hline Cerebral vascuolopathy, n (\%) & $15(6)$ & $9(7)$ & $6(5)$ & .792 \\
\hline Degenerative atherosclerotic aneurysm, $\mathrm{n}(\%)$ & $156(63)$ & $87(64)$ & $69(62)$ & .701 \\
\hline Chronic postdissection aneurysm, $\mathrm{n}(\%)$ & $86(35)$ & $45(33)$ & $41(37)$ & .562 \\
\hline Acute type A dissection, $\mathrm{n}(\%)$ & $5(2)$ & $4(3)$ & $1(1)$ & .382 \\
\hline Elective, n (\%) & $236(95)$ & $127(93)$ & $109(97)$ & .150 \\
\hline Urgent/emergency, n (\%) & $12(5)$ & $9(7)$ & $3(3)$ & .150 \\
\hline LVEF, n (\%) & & & & .413 \\
\hline$>55 \%$ & $227(92)$ & $122(90)$ & $105(94)$ & \\
\hline $35 \%-55 \%$ & $16(7)$ & $10(7)$ & $6(5)$ & \\
\hline$<35 \%$ & $5(2)$ & $4(3)$ & $1(1)$ & \\
\hline
\end{tabular}

Renal failure is defined as creatinine $>200 \mu \mathrm{mol} / \mathrm{L}$; hypertension is defined as a history of systemic artery hypertension. $E T$, Elephant trunk; $S D$, standard deviation; $C O P D$, chronic obstructive pulmonary disease (long-term use of bronchodilators or steroids for lung disease); $C A D$, coronary artery disease; $L V E F$, left ventricular ejection fraction.

less than .05 were retained. The statistical software package SPSS 20 (SPSS Inc, Chicago, Ill) was used for the analysis.

\section{RESULTS \\ Patient Population}

A total of 248 consecutive patients underwent an ET procedure for extensive thoracic aortic disease. The mean age was 65 years (standard deviation, 10 years; range, 21-79 years). One hundred nine $(44 \%)$ of the patients were male. Twenty patients $(8 \%)$ were diagnosed with Marfan syndrome. Sixty-one patients $(25 \%)$ had a history of previous cardiac surgery; 34 (14\%) had supracoronary ascending aorta replacements, $21(9 \%)$ had Bentall procedures, $4(2 \%)$ had aortic valve replacements, $2(1 \%)$ had coronary artery bypass grafts, and $2(1 \%)$ had mitral valve surgeries. The preoperative data are listed in Table 1.

\section{Surgical Outcomes}

First-stage ET. All 248 patients underwent arch replacement and ET. Concomitant aortic procedures included Bentall in 80 patients $(32 \%)$, aortic valve replacement in 21 patients $(9 \%)$, and aortic valve repair/sparing in 10 patients $(4 \%)$. Other associated procedures are listed in Table 2 . The mean cardiopulmonary bypass and myocardial ischemia times were $223 \pm 69$ minutes and $134 \pm 44$ minutes, respectively. The ASCP and total circulatory arrest times were $86 \pm 37$ minutes and $61 \pm 29$ minutes, respectively. Cerebral protection was achieved using unior bilateral ASCP in 207 patients (86\%), deep hypothermic circulatory arrest in $8(3 \%)$, or a combination of both in 26 $(11 \%)$. Urgent/emergency procedures were performed in 12 patients $(5 \%)$. There were no intraoperative deaths. In-hospital mortality was $8 \%$ (20 patients). In elective cases, in-hospital mortality was 7\% (17 of 236); in-hospital mortality occurred in $25 \%$ (3 of 12) of urgent/emergency cases. In-hospital mortality was $8 \%$ (14 of 187) in patients who underwent ET as the first cardiac intervention, compared with $10 \%$ (6 of 61) in patients with previous cardiac surgery $(P=.558)$. During hospitalization, 57 patients $(23 \%)$ underwent rethoracotomy for bleeding. Left recurrent nerve palsy occurred in $20(8 \%)$ and permanent neurologic deficits were observed in 5 patients $(2 \%)$. Median admission to the intensive care unit (ICU) was 4 days (range, 2-24 days) and the median hospital stay was 13 days (range, 5-75 days). The postoperative adverse events are listed in Table 2.

Second-stage ET planning. The second-stage operation was planned for 125 patients; in this group, the mean diameter of the descending aortic was $62 \pm 9 \mathrm{~mm}$. Eight patients died before the planned second-stage procedure could be performed: 1 had a rupture of the remote aneurysm, 2 had a prosthetic infection, 1 an aortopulmonary fistula, 1 died of heart failure, 1 of multiorgan failure, 1 after 
TABLE 2. Intraoperative characteristics and adverse events after the first stage

\begin{tabular}{|c|c|}
\hline Characteristic & Findings \\
\hline \multicolumn{2}{|l|}{ Operation associated with ET, n (\%) } \\
\hline Bentall & $80(32)$ \\
\hline Aortic valve replacement & $21(9)$ \\
\hline Aortic valve repair/sparing & $10(4)$ \\
\hline CABG & $49(20)$ \\
\hline Mitral valve repair & $3(1)$ \\
\hline Mitral valve replacement & $1(0.4)$ \\
\hline \multicolumn{2}{|l|}{ Methods of brain protection, $\mathrm{n}(\%)$} \\
\hline ASCP & $207(86)$ \\
\hline ASCP + deep cooling & $26(11)$ \\
\hline Deep cooling $\left(18^{\circ} \mathrm{C}\right)$ & $8(3)$ \\
\hline \multicolumn{2}{|l|}{ Arch vessel reimplantation, $\mathrm{n}(\%)$} \\
\hline Island & $132(53)$ \\
\hline Separated & $90(36)$ \\
\hline Island + separated & $6(2)$ \\
\hline \multicolumn{2}{|l|}{ Operative times, $\min \pm \mathrm{SD}$} \\
\hline $\mathrm{CPB}$ & $223 \pm 69$ \\
\hline Myocardial ischemia & $134 \pm 44$ \\
\hline Visceral ischemia & $61 \pm 29$ \\
\hline ASCP & $86.2 \pm 37$ \\
\hline \multicolumn{2}{|l|}{ Complications after first stage, $\mathrm{n}(\%)$} \\
\hline In-hospital death & $20(8)$ \\
\hline Permanent neurologic deficit & $5(2)$ \\
\hline Temporary neurologic damage & $2(1)$ \\
\hline Left recurrent nerve injury & $20(8)$ \\
\hline Spinal cord injury & $0(0)$ \\
\hline Respiratory failure & $2(1)$ \\
\hline Temporary dialysis & $2(1)$ \\
\hline Permanent dialysis & $0(0)$ \\
\hline Acute myocardial infarction & $3(1)$ \\
\hline Bleeding requiring rethoracotomy & $57(23)$ \\
\hline PM implantation & $5(2)$ \\
\hline Mediastinitis & $10(4)$ \\
\hline ICU stay, d (range) & $4(2-24)$ \\
\hline Total hospital stay, d (range) & $13(5-75)$ \\
\hline
\end{tabular}

pseudoaneurysm repair from the proximal anastomosis, and 1 of an unknown cause. Five patients (mean descending aortic diameter, $61 \mathrm{~mm}$; range, $50-70 \mathrm{~mm}$ ) are presently still waiting for the second stage. In the remaining 103 patients, the diameter of the downstream aneurysm has not yet reached the surgical indication.

Second-stage ET. Of all patients who underwent firststage ET surgery, $112(45 \%)$ underwent second-stage ET. In 87 patients $(77 \%)$ this was performed surgically, with a partial or total descending aortic replacement (17 patients) or a thoracoabdominal repair (70 patients). In the remaining 25 patients $(23 \%)$, the second stage was performed via thoracic endovascular aortic repair (TEVAR).

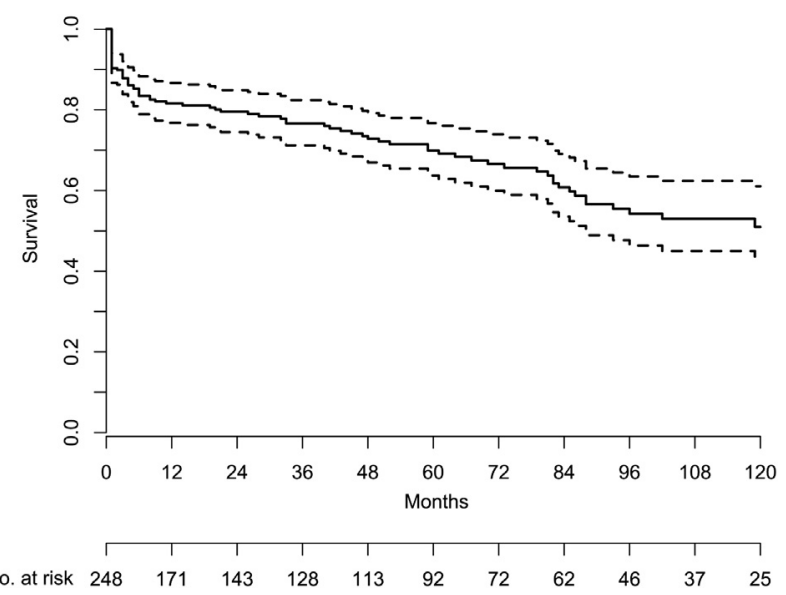

FIGURE 1. Kaplan-Meier survival curve: 5-year survival for the total elephant trunk group.

Overall in-hospital mortality after second-stage ET was $8 \%$ (9 patients; 8 patients in the surgical group and 1 in the TEVAR group). Paraplegia was observed in 9 patients ( 8 in the surgical group and 1 in the TEVAR group); all these patients presented with an aortic aneurysm extending to the abdominal aorta. There were other complications in the surgical group, such as gastrointestinal complications in 3 patients, respiratory failure in 3, and rethoracotomy as a result of excessive bleeding in 2. No periprocedural stroke was recorded after second-stage ET.

Follow-up. The median follow-up after first-stage ET was 48 months (range, 1-210 days). The median interval between the first and second stage was 6 months (range, 1-111 months). In the patients who underwent second-stage ET, the median follow-up was 39 months (range, 1-206 months).

\section{Long-Term Results}

Overall survival after first-stage ET was $75 \%$ and $67 \%$ at 5 and 10 years follow-up, respectively (Figure 1). Survival in the group with second-stage ET was $87 \%$, compared with

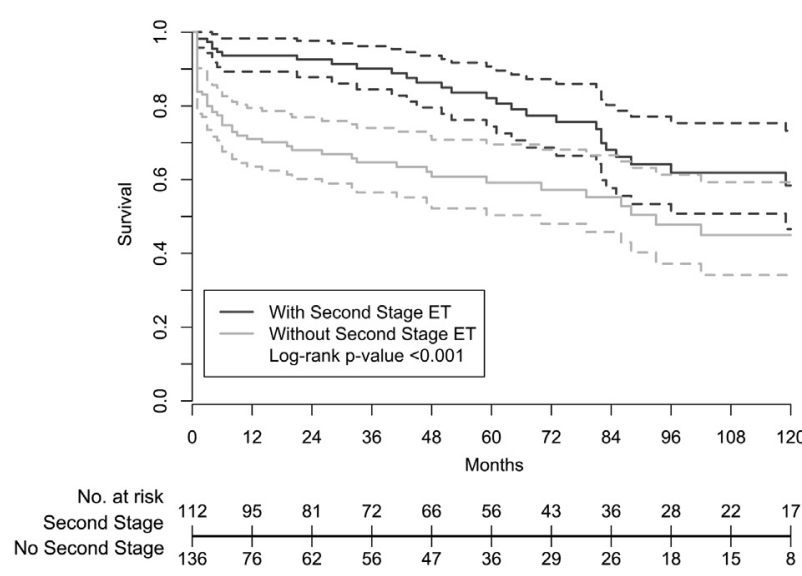

FIGURE 2. Kaplan-Meier survival curve: patients with and without second-stage elephant trunk (ET) technique. 


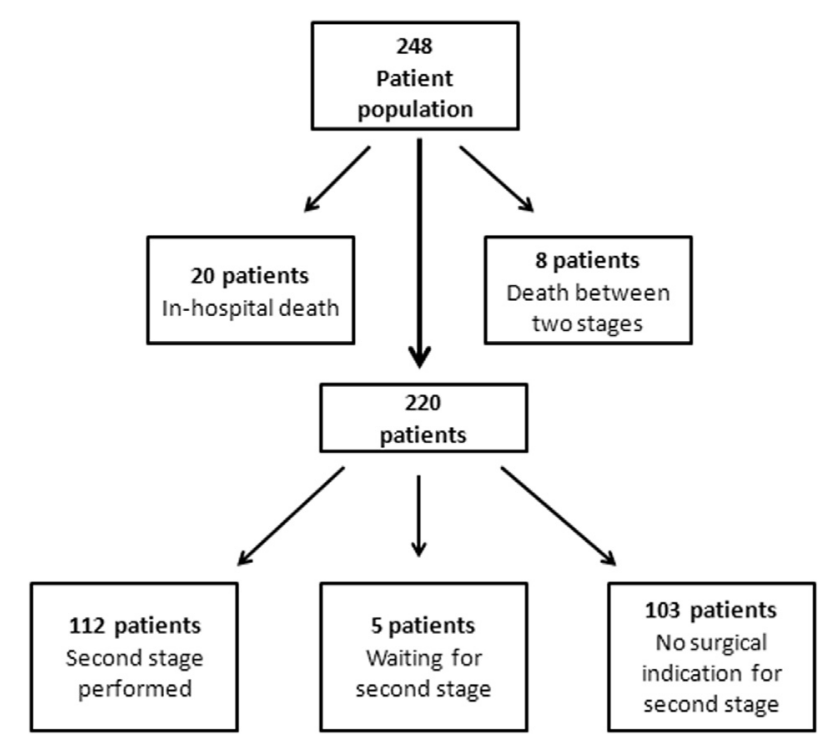

FIGURE 3. Flowchart showing how patients were treated and withdrawals because of death.

$65 \%$ in the group who had not undergone the second stage at the 5-year follow-up $(P<.001)$ and $67 \%$ compared with $36 \%$ at the 10-year follow-up (log-rank, $P<.001$; Figure 2). Firststage outcomes were analyzed in all 248 patients to find univariate predictors of mortality. Multivariate logistic regression analyses of all patients showed that the absence of second-stage ET was the only predictor for mortality (odds ratio, 1.745; confidence interval, 1.015-3.001; $P=.044$ ).

\section{DISCUSSION}

Combined disease of the aortic arch and the descending aorta is a surgical challenge. However, the staged ET technique $^{12-14}$ is currently the most widely adopted technique. The original technique developed by Borst and colleagues $^{5}$ was modified by Crawford and colleagues ${ }^{8}$ with placement of the inverted graft in the descending aorta and extension of the free portion into the descending aorta. Starting in 1995, a TEVAR approach was introduced for second-stage completion of the aortic repair. ${ }^{15-17}$ Other techniques that have been developed include the hybrid surgical/endovascular approach, the so-called frozen elephant trunk, ${ }^{18,19}$ and the aortic arch debranching and stenting techniques. $^{20,21}$

In this study, we report on the outcomes of the 2-stage ET technique, updating the previous report from $2002 .^{10}$

Over the past 3 decades, building on Borst and colleague's innovative idea, the indications for this technique have been revised. In the early experience, this treatment was applied only to patients with aneurysmal disease, and was later extended to those with chronic and acute aortic dissection.

There are 2 major advantages to using the staged approach for thoracic aortic repair. First, during the second stage, the proximal area between the distal aortic arch and the descending aortic graft is avoided, preventing potential injury to the anatomic structures near the descending thoracic aorta (eg, pulmonary artery, esophagus, vagus and recurrent nerves, and thoracic duct). Second, the proximal anastomosis can be carried out more rapidly, reducing the risk of ischemic visceral complications. Moreover, the risks of cerebral neurologic complications are lower when clamping the ET compared with clamp placement proximal to the left subclavian artery.

Modern grafts with 4 side branches have reduced cardiopulmonary bypass, myocardial ischemic, and lower body ischemic times during the first stage. ${ }^{22}$ If an endovascular second approach is planned, the use of metal clips in the distal portion of the ET is necessary to allow accurate determination of the endoprosthesis landing zone. $^{16}$

The choice of adequate trunk length is crucial; an undersized trunk makes gripping and clamping very difficult during the second stage, whereas an oversized trunk can cause hypoperfusion of the spinal cord with increased risks of paraplegia. In our series, no complications occurred with regard to spinal cord injury (SCI) after the first stage.

In cases of chronic aortic dissection, the intimal flap must be removed longitudinally for a length greater than that of the ET to avoid its entrapment and equalize perfusion in both the false and the true lumina; caution must be taken when the false lumen contains mural thrombus. There were no entrapments of the ET in our series. However, in 1 patient treated for acute aortic dissection, ET kinking caused lower body hypoperfusion and eventually led to multiorgan failure and death.

Another important issue is the interval between the first and second stage; ideally, this should be as brief as possible. Patients with an indication for a second-stage procedure can be divided into 2 groups: the first with an urgent indication for the second stage (because of the size or a symptomatic lesion in the descending thoracic aorta), the second with an elective indication (with stable growth of the aneurysm and no symptoms). However, for both groups, the surgical timing is not easy to determine, because we must consider recovery from the first surgery and other related medical conditions that can greatly increase surgical risk.

There is also a third group of patients whose descending thoracic aorta has not yet reached a diameter demanding second-stage repair; these patients should be monitored carefully using CT.

In our series, only $45 \%$ of patients underwent a second stage; excluding patients who died after the first surgery $(\mathrm{n}=20)$, those who died between the 2 stages $(\mathrm{n}=8)$, and those who are on the waiting list $(\mathrm{n}=5)$, this still leaves a large proportion of patients $(n=103)$ who have not reached a critical diameter of the descending thoracic aorta 
and are being followed closely (Figure 3). Mean diameter in this follow-up group was $50 \pm 11 \mathrm{~mm}$. The reason for this large number of patients is because we believe that mortality and morbidity for the first-stage classic ET is similar to that of a total arch replacement without ET with the advantage of smoother surgical performance during any subsequent downstream aortic surgery, be it open or endovascular. Therefore, even patients with a noncritical descending thoracic aorta diameter are often treated with ET, especially if they are young. This policy is also adopted by other institutions. ${ }^{23}$

Another open issue is the use of ET in cases of acute dissection. Some surgeons advocate only an ascending aorta or hemiarch replacement with aortic valve resuspension or valve-sparing procedures. ${ }^{24}$ However, several studies have shown a high incidence of dilatation of the distal aorta in patients who survived the first surgery, which may lead to poor outcomes. ${ }^{25,26}$ Other authors have proposed total aortic arch replacement with ET to facilitate any subsequent surgery of the thoracic aorta. ${ }^{27}$ However, management remains controversial because of the greater technical complexity of the latter approach. In addition, the long-term benefits remain to be confirmed. In our series, only 5 patients $(2 \%)$ had a preoperative diagnosis of acute aortic dissection.

Since the early 1990s, new prostheses have been developed for the treatment of concomitant aortic arch and proximal descending aorta disease using the socalled frozen ET (FET) technique. With this technique, the aortic arch is replaced in a traditional manner and a stented graft is placed in the descending thoracic aorta through the open arch using an antegrade approach. ${ }^{19,28,29}$ The landing site should be free from disease to ensure proper anchoring of the stent graft. Subsequently, either open or endovascular procedures can be performed to treat the downstream aorta. Although this approach was initially intended to avoid second-stage operations after the classic ET, its indications were extended to patients with acute aortic dissections and mega-aortic syndrome. The advantages of the radially expanding stent graft include effective single-stage treatment of arch aneurysms limited to the proximal descending aorta, prevention of anastomotic leakage, and reduction of the risk of kinking of the prosthesis. In cases of aortic dissection, the stent graft seals descending aortic tears, with expansion of the true lumen and compression of the false lumen, preventing further growth of the proximal descending aorta. ${ }^{16,18,19,28-30}$

A major disadvantage of the FET technique seems to be an increased risk of SCI and much higher risk of renal failure compared with the results we describe in our series with the classic ET technique. ${ }^{31}$ SCI in FET procedures seems to be multifactorial but likely related to the coverage of the intercostal arteries between $\mathrm{T} 6$ and $\mathrm{T} 8 .^{32}$ The
International E-vita Open Registry reported an SCI rate of $8.0 \%{ }^{30}$ Although paraparesis and paraplegia resolved partially in $40 \%$ of these cases, they remain notable complications. In a meta-analysis on FET in arch surgery, the overall prevalence of postoperative SCI was lower $(5.1 \%)$, partially attributed to institutional modification of FET length. ${ }^{33}$ No SCI occurred in our study using the classic ET during the first-stage procedure, although $8 \%$ (9 patients) presented SCI after second-stage ET. However, all of these patients had thoracoabdominal aneurysms, necessitating a second-stage procedure regardless of whether they were treated using FET or not. Moreover, the thoracoabdominal aneurysm further complicates repair after FET as more intercostal arteries have been covered by the endoprosthesis or, in the case of aortic dissection, occluded by progression of downstream thrombus formation.

Regarding postoperative renal failure after FET, the same meta-analysis $^{33}$ reports a prevalence of $11 \%$. In cases of chronic aortic dissection, in particular, the origin of the renal arteries (either in the true or the false lumen, and the presence of potential distal reentry) should be evaluated preoperatively to curtail the risk of distal organ perfusion after open stent grafting. In our series, we report an incidence of postoperative renal failure of $1 \%$. Another disadvantage is the high cost compared with the classic ET technique.

We report a high incidence of postoperative bleeding requiring rethoracotomy after the first-stage procedure $(23 \%)$. This is because our policy is to start warfarin therapy on the first postoperative day, and our strategy is to perform rethoracotomy for bleeding with a low threshold and before clear signs of cardiac tamponade present. Moreover, some of these rethoracotomies were late, more than 1 week postoperatively, for which percutaneous draining was impossible because of the unsuitable localization of the intrapericardial blood.

In conclusion, the classic ET technique for diffuse aortic disease is a relatively safe method with acceptable early outcomes. The mortality rate after the first stage justifies the use of the classic ET to allow successive surgical or endovascular repair of the distal aorta. Long-term survival is increased when both stages are completed.

\section{Strengths and Limitations}

The strengths of the present analysis include the very long-term follow-up and unique patient population; all patients were operated on in a single center, ensuring uniform patient care. The retrospective nature of this study means that no definite conclusions may be drawn regarding the efficacy of the procedure. However, the consistent and long-term follow-up combined with the large number of patients included may counterbalance this to a degree. 
Our thanks to Dr Bastiaan Geelhoed for his assistance with the figures.

\section{References}

1. Rokkas CK, Kouchoukos NT. Single-stage extensive replacement of the thoracic aorta: the arch-first technique. J Thorac Cardiovasc Surg. 1999;117: 99-105.

2. Massimo CG, Perna AM, Cruz Quadron EA, Arounian RV. Extended and total simultaneous aortic replacement: latest technical modifications and improved results with thirty-four patients. J Card Surg. 1997;12:261-9.

3. Svensson LG, Shahian DM, Davis FG, Entrup MH, Kimmel WA, McGrath DM, et al. Replacement of entire aorta from aortic valve to bifurcation during one operation. Ann Thorac Surg. 1994;58:1164-6.

4. Crawford ES, Svensson LG, Coselli JS, Safi HJ, Hess KR. Surgical treatment of aneurysm and/or dissection of the ascending aorta, transverse aortic arch, and ascending aorta and transverse aortic arch: factors influencing survival in 717 patients. J Thorac Cardiovasc Surg. 1989;98:659-74.

5. Borst HG, Walterbusch G, Schaps D. Extensive aortic replacement using elephant trunk prosthesis. Thorac Cardiovasc Surg. 1983;31:37-40.

6. Hiratzka LF, Bakris GL, Beckman JA. 2010 ACCF/AHA/AATS/ACR/ ASA/SCA/SCAI/SIR/STS/SVM guidelines for the diagnosis and management of patients with thoracic aortic disease: a report of the American College of Cardiology Foundation/American Heart Association Task Force on Practice Guidelines, American Association for Thoracic Surgery, American College of Radiology, American Stroke Association, Society of Cardiovascular Anesthesiologists, Society for Cardiovascular Angiography and Interventions, Society of Interventional Radiology, Society of Thoracic Surgeons, and Society for Vascular Medicine. Circulation. 2010;121:e266-369.

7. Dossche KM, Schepens MA, Morshuis WJ, Muysoms FE, Langemeijer JJ, Vermeulen FE. Antegrade selective cerebral perfusion in operations on the proximal thoracic aorta. Ann Thorac Surg. 1999;67:1904-10.

8. Crawford ES, Coselli JS, Svensson LG, Safi HJ, Hess KR. Diffuse aneurysmal disease (chronic aortic dissection, Marfan, and mega aorta syndromes) and multiple aneurysm. Treatment by subtotal and total aortic replacement emphasizing the elephant trunk operation. Ann Surg. 1990; 211:521-37.

9. Svensson LG, Rushing GD, Valenzuela ES, Rafael AE, Batizy LH, Blackstone EH, et al. Modifications, classification, and outcomes of elephanttrunk procedures. Ann Thorac Surg. 2013;96:548-58.

10. Schepens MA, Dossche KM, Morshuis WJ, van den Barselaar PJ, Heijmen RH, Vermeulen FE. The elephant trunk technique: operative results in 100 consecutive patients. Eur J Cardiothorac Surg. 2002;21:276-81.

11. Neri E, Massetti M, Sani G. The "elephant trunk" technique made easier. Ann Thorac Surg. 2004;78:e17-8.

12. LeMaire SA, Carter SA, Coselli JS. The elephant trunk technique for staged repair of complex aneurysms of the entire thoracic aorta. Ann Thorac Surg. 2006;81:1561-9.

13. Etz CD, Plestis KA, Kari FA, Luehr M, Bodian CA, Spielvogel D, et al. Staged repair of thoracic and thoracoabdominal aortic aneurysms using the elephant trunk technique: a consecutive series of 215 first stage and 120 complete repairs. Eur J Cardiothorac Surg. 2008:34:605-14.

14. Safi HJ, Miller CC III, Estrera AL, Huynh TT, Porat EE, Allen BS, et al. Staged repair of extensive aortic aneurysms: long-term experience with the elephant trunk technique. Ann Surg. 2004;240:677-84.
15. Fann JI, Dake MD, Semba CP, Liddell RP, Pfeffer TA, Miller DC. Endovascular stent-grafting after arch aneurysm repair using the 'elephant trunk'. Ann Thorac Surg. 1995;60:1102-5.

16. Greenberg RK, Haddad F, Svensson L, O'Neill S, Walker E, Lyden SP, et al. Hybrid approaches to thoracic aortic aneurysms: the role of endovascular elephant trunk completion. Circulation. 2005;112:2619-26.

17. Matsuda H, Tsuji Y, Sugimoto K, Okita Y. Secondary elephant trunk fixation with endovascular stent grafting for extensive/multiple thoracic aortic aneurysm. Eur J Cardiothorac Surg. 2005;28:335-6.

18. Kato M, Ohnishi K, Kaneko M, Ueda T, Kishi D, Mizushima T, et al. New graft-implanting method for thoracic aortic aneurysm or dissection with a stented graft. Circulation. 1996;94(Suppl II):II188-93.

19. Di Eusanio M, Pantaleo A, Murana G, Pellicciari G, Castrovinci S, Berretta P, et al. Frozen elephant trunk surgery-the Bologna's experience. Ann Cardiothorac Surg. 2013;2:597-605.

20. Buth J, Penn O, Tielbeek A, Mersman M. Combined approach to stentgraft treatment of an aortic arch aneurysm. J Endovasc Surg. 1998;5:329-32.

21. Czerny M, Zimpfer D, Fleck T, Hofmann W, Schoder M, Cejna M, et al. Initial results after combined repair of aortic arch aneurysms by sequential transposition of the supra-aortic branches and consecutive endovascular stent-graft placement. Ann Thorac Surg. 2004;78:1256-60.

22. Di Eusanio M, Schepens MA, Morshuis WJ, Dossche KM, Kazui T, Ohkura K, et al. Separate grafts or en bloc anastomosis for arch vessels reimplantation to the aortic arch. Ann Thorac Surg. 2004;77:2021-8.

23. Shrestha M, Martens A, Krüger H, Maeding I, Ius F, Fleissner F, et al. Total aortic arch replacement with the elephant trunk technique: single-centre 30-year results. Eur J Cardiothorac Surg. 2014;45:289-95.

24. Westaby S, Saito S, Katsumata T. Acute type A dissection: conservative methods provide consistently low mortality. Ann Thorac Surg. 2002;73:707-13.

25. Tsai TT, Trimarchi S, Nienaber CA. Acute aortic dissection: perspectives from the International Registry of Acute Aortic Dissection (IRAD). Eur J Vasc Endovasc Surg. 2009;37:149-59.

26. Fattouch K, Sampognaro R, Navarra E, Caruso M, Pisano C, Coppola G, et al. Long-term results after repair of type a acute aortic dissection according to false lumen patency. Ann Thorac Surg. 2009;88:1244-50.

27. Miyamoto S, Hadama $\mathrm{T}$, Anai $\mathrm{H}$, Wada $\mathrm{T}$, Iwata $\mathrm{E}$, Tanaka $\mathrm{H}$, et al. Simplified elephant trunk technique promotes thrombo-occlusion of the false lumen in acute type A aortic dissection. Ann Thorac Cardiovasc Surg. 2006;12:412-6.

28. Shrestha M, Pichlmaier M, Martens A, Hagl C, Khaladj N, Haverich A. Total aortic arch replacement with a novel four-branched frozen elephant trunk graft: first-in-man results. Eur J Cardiothorac Surg. 2013;43:406-10.

29. Di Eusanio M, Petridis FD, Pacini D, Di Bartolomeo R. Facilitated aortic arch repair with the frozen elephant trunk technique. Eur J Cardiothorac Surg. 2011;40:1261-2.

30. Jakob H, Tsagakis K, Pacini D, Di Bartolomeo R, Mestres C, Mohr F, et al. The International E-vita Open Registry: data sets of 274 patients. J Cardiovasc Surg (Torino). 2011:52:717-23

31. Ius F, Hagl C, Haverich A, Pichlmaier M. Elephant trunk procedure 27 years after Borst: what remains and what is new? Eur J Cardiothorac Surg. 2011; 40:1-12.

32. Flores J, Kunihara T, Shiiya N, Yoshimoto K, Matsuzaki K, Yasuda K. Extensive deployment of the stented elephant trunk is associated with an increased risk of spinal cord injury. J Thorac Cardiovasc Surg. 2006;131:336-42.

33. Tian DH, Wan B, Di Eusanio M, Black D, Yan TD. A systematic review and meta-analysis on the safety and efficacy of the frozen elephant trunk technique in aortic arch surgery. Ann Cardiothorac Surg. 2013;2:581-91. 